\title{
MODERN TRENDS IN THE DEVELOPMENT OF MATHEMATICAL MODELING IN THE EPOCH OF DIGITAL TECHNOLOGIES
}

\author{
Jawad Kadhim Tahir \\ Mustansiriyah University \\ Education College \\ Computer Sciences Department
}

\begin{abstract}
The article analyzes the concept and significance of mathematical modeling. Particular importance is given to the trends of recent years, which is caused by the sharp development of digital technologies. As an example, a mathematical model is presented, which can solve the problem of forecasting the development of the municipality. In the framework of the work, a number of regression equations of the model are presented, which make it possible to forecast the key indicators of the socio-economic development of the municipality.
\end{abstract}

Key words: Mathematical model, digital technologies, regression equation, forecast of socio-economic development.

1. Introduction The purpose of this study is to study current trends in the development of mathematical modeling in the era of digital technology. In the framework of this work, it is necessary to identify the main features of the use of digital technologies in mathematical modeling, to give an example of the use of mathematical modeling to solve certain problems, in particular, the forecast of the socio-economic development of a municipality.

Nowadays, mathematics has a significant impact on human activity. In this case, attention should be paid to the fact that the degree of its development depends on various factors, and its role has developed historically. These factors include the development of mathematical concepts and the mathematical apparatus, as well as the degree of development of digital technologies. Note that in the case when the description of mathematical processes and phenomena is more accurate, this will lead to the appearance of more complex systems, equations, and inequalities that can be 
solved using conventional analytical methods, which will affect the application of computational algorithms with using computer technology, in particular computers.

Such a direction as mathematical modeling is quite young, and today it can be noted that in connection with the development of digital technologies, the development of this scientific direction continues.

The relevance of this topic is determined by the fact that today there is a constant development of computer technology and systems, which requires, in turn, a reassessment of previously developed algorithms, the study of the possibility of their adaptation with new and improved architectures.

Various researchers paid attention to these issues in their works, in particular, A. Abdykarimov. [1], Volkova L.F. [2], Gareeva G.A. [3], Dreisis, Yu.I. [4], Zvyagin L.S. [5], Zmeeva Yu.V. [6], Smetanina A.O. [7], Pavel Prazak [8], Vladimir Bures [8], Steven R. Dunbar [9], Michael Alder [10], Pavlov Y [11].

However, due attention to the development trends of mathematical modeling in the digital age is not analyzed in the works of these authors and other works. All this confirms the relevance of the topic.

2. Results and discussions Scientific methodology and use of appropriate methods are the basis for the organization and conducting of scientific research. Proceeding from this, to solve the above problems, general scientific research methods were used, in particular, such as analysis and synthesis of scientific literature, comparison and generalization of research materials from various sources. In the framework of this work, mathematical methods for solving problems were used, in particular mathematical modeling and regression equations.

In order to examine certain phenomena, build a mathematical model that allows us to give an approximate description of the phenomenon under investigation [5]. Note the view of Y.I. Dreisis [4] regarding the stages of mathematical modeling based on the development of information technology as shown in figure 1. 


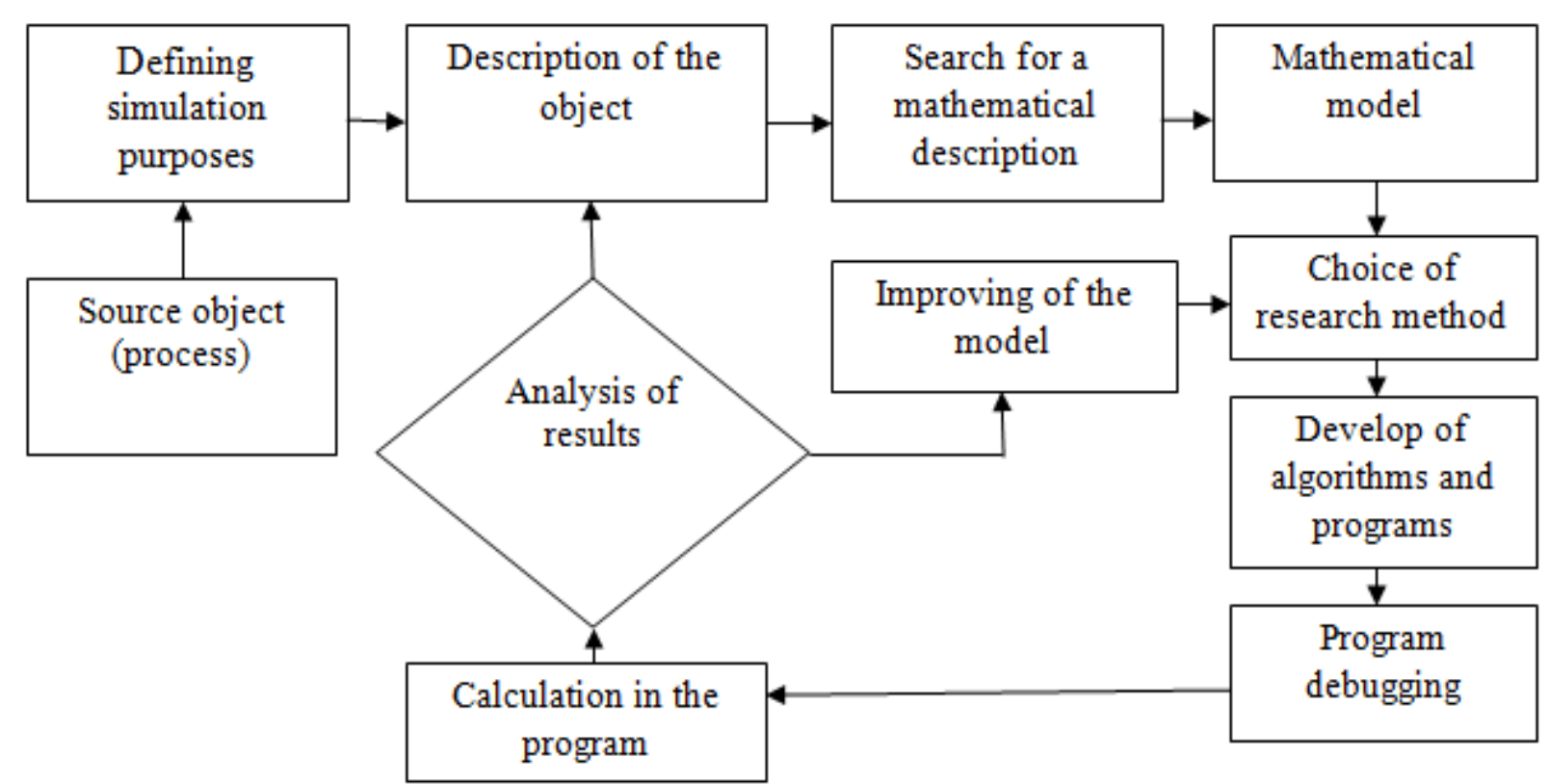

Fig. 1. Stages of mathematical modeling with the development of information technology

In the framework of the topic under discussion, the presentation of the scheme of the mathematical model itself, which takes place in the digital technologies epoch, will be equally important.

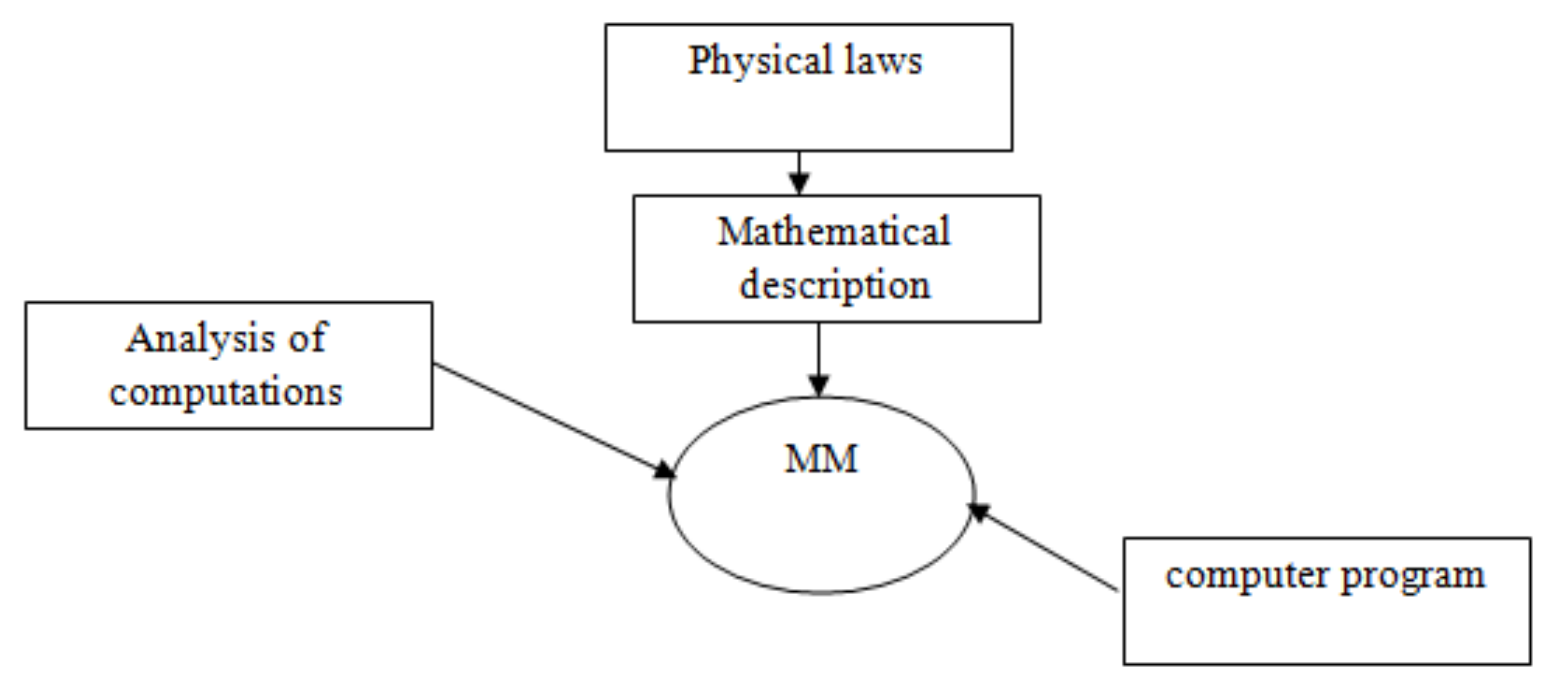

Fig. 2. Scheme of the mathematical model 
As noted by G.A. Gareeva [3], the mathematical modeling method has become one of the most popular methods. We note the fact that the magnitude of the scale of development of modern society, the rate of updating and complication, leads to the fact that there is an urgent need for processing large amounts of information that are constantly increasing. It became the prerequisite for the development of computers, which was also associated, on the one hand, with the development of the electronics industry, as well as with the growing needs of physicists, mathematicians, and other specialists in the automation of calculations. This led to the fact that for a sufficiently long period of time computers were used only as a tool for scientific mathematical calculations, A.T. Abdykarimova noted that the processing of large amounts of information is characteristic in the process of its production activities for most organizations and businesses. This is one of the main reasons for the continuous development of digital technologies, which facilitates and accelerates the process of mathematical modeling [1].

Thus, we note that the continuous development of digital technology makes it possible each time to speed up the process of mathematical modeling, which in turn has a positive effect on the process of decision-making.

All of the above allows us to note that today, with the help of information technologies and the theory of mathematical modeling, it is possible to solve administrative, medical, economic and other problems of varying complexity. In the era of digital development, mathematical modeling has particular importance in predicting the socio-economic development of the municipality.

Accordingly, it is necessary to solve the above problems which contributed the development of mathematical models, as well as the creation of algorithms for solving them.

Note that the development of digital technologies has provided great opportunities for more information processing in various areas of society, which we will consider in more detail below.

1. Information technology and theory of mathematical modeling in education. In this case, the given possibilities are limitless, with their help, fundamental changes can occur in the curriculum and teaching aids. 
2. Using IT and mathematical modeling in medical practice. This is one of the most obvious examples of the application of mathematical modeling with the advent of computer technology and software is indispensable for solving complex modern medical research. Such studies include computed tomography, ultrasonography, studies using isotopes. The data that medical workers obtain from these studies are quite massive and without the use of IT and the theory of mathematical modeling, an ordinary person can not perceive them and even more so process it.

3. Automation of production processes. Today, the development of digital technologies is also quite important for managers of various ranks, since the most common problem that they have always encountered is the problem of making managerial decisions, using mathematical modeling and availability of the necessary equipment can significantly speed up and facilitate this process.

4. Experiment management. Using of information technology and mathematical modeling in this case is undeniable, since during the experiment, a situation is recreated that naturally observed either difficult or not possible. Methods of mathematical modeling using computer technology are used in this case in order to simulate such situations.

5. Application of game theory, note that the mathematical model of a real conflict situation is characterized by an analysis based on specific rules of a game.

6. Mathematical modeling has particular importance in solving problems in the economy, in particular forecasting socio-economic development. the forecasting process in the municipality with the advent of digital technologies has become more efficient and making government decisions takes time less than before.

We directly introduce a mathematical model that allows us to solve a problem as effective forecasting of the socio-economic development of municipality, therefore the economic and mathematical modeling of the process represents aspecific system. 


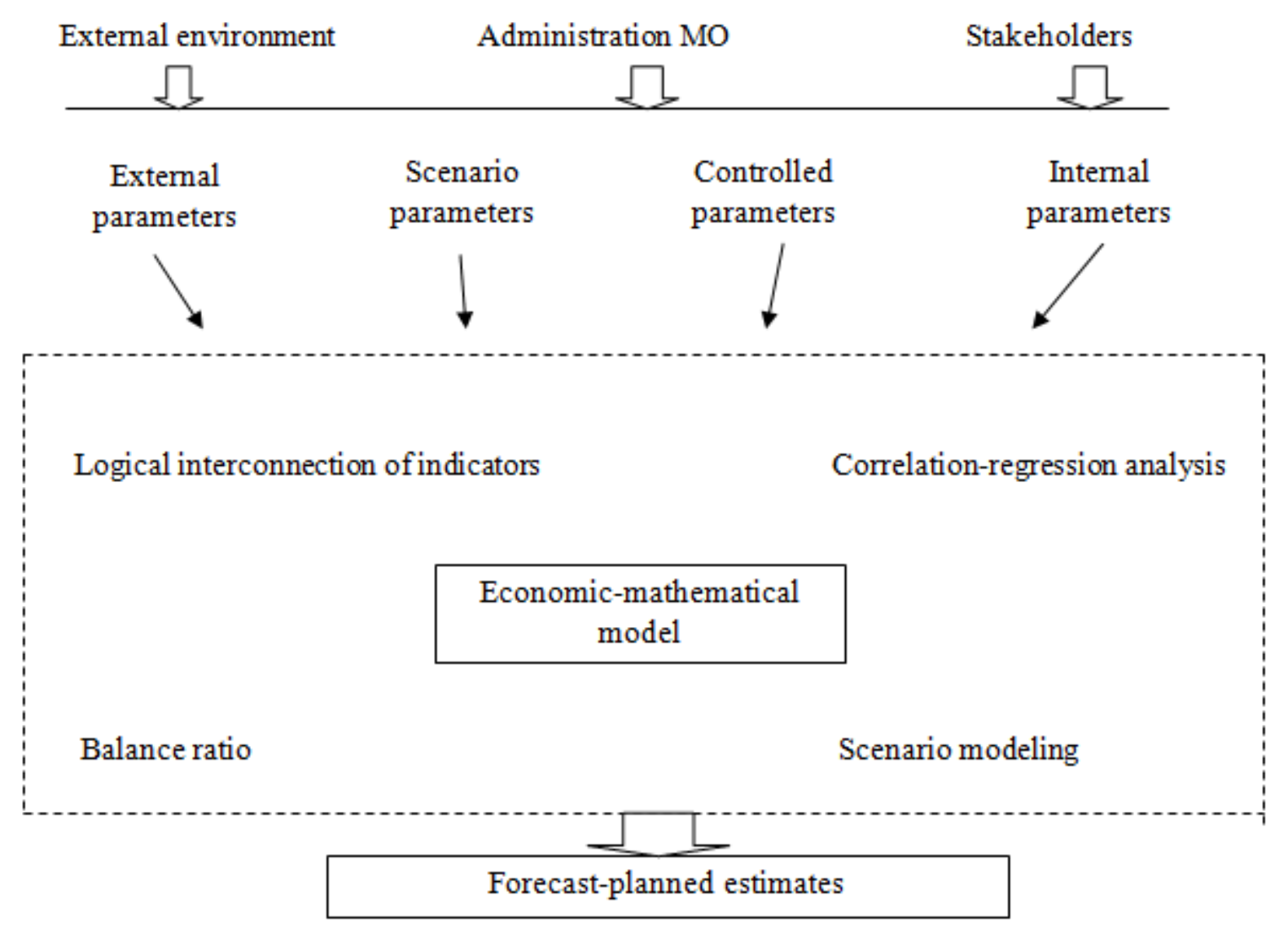

Fig. 3. System for the development of economic and mathematical model of municipal formation

The development trend of the environment the macroeconomic situation are considered in the modeling due to the high degree of open municipal systems. To develope a mathematical model, it is necessary to take into account some indicators such as the consumer price index and the growth rate of the gross regional product, in which the municipality is located, the standard of living in neighboring municipalities and the whole region, parameters of budgetary tax system etc. e basis of the mathematical model is the development of a set of balance and regression equations that ensure a logical relationship of parameters, that allows to predict socio-economic development. Noted that with the help of the developed model tools, it becomes possible to justify the main parameters related to the socio-economic development of the municipality and will allow further assessment of the consequences after the implementation of measures, as well as to establish the influence of environmental factors. 
Note that the basis of the mathematical model will be the regression equation:

$Y_{x}=a_{0}+a_{i} \times X$

where $\mathrm{X}$ - factorial indicator

$Y_{x}$ - effective indicator

$\mathrm{a}_{0}$ - free parameter of the equation that characterizes the level of the productive attribute $(\mathrm{X}=0)$

$a_{i}-$ regression coefficient. It shows how much the effective trait will change if the factor increases by one.

We presented the main indicators that must be used in constructing a mathematical model that can effectively predict the socio-economic development of the municipality as shown in figure 4, It list of indicators that allow us to analyze the development of the city in such blocks as: the social sphere, the city's economy, and municipal finance. When the logical model of the municipality is formed, it is necessary to move on mathematical formalization. Based on this, the most suitable is the use of economic.

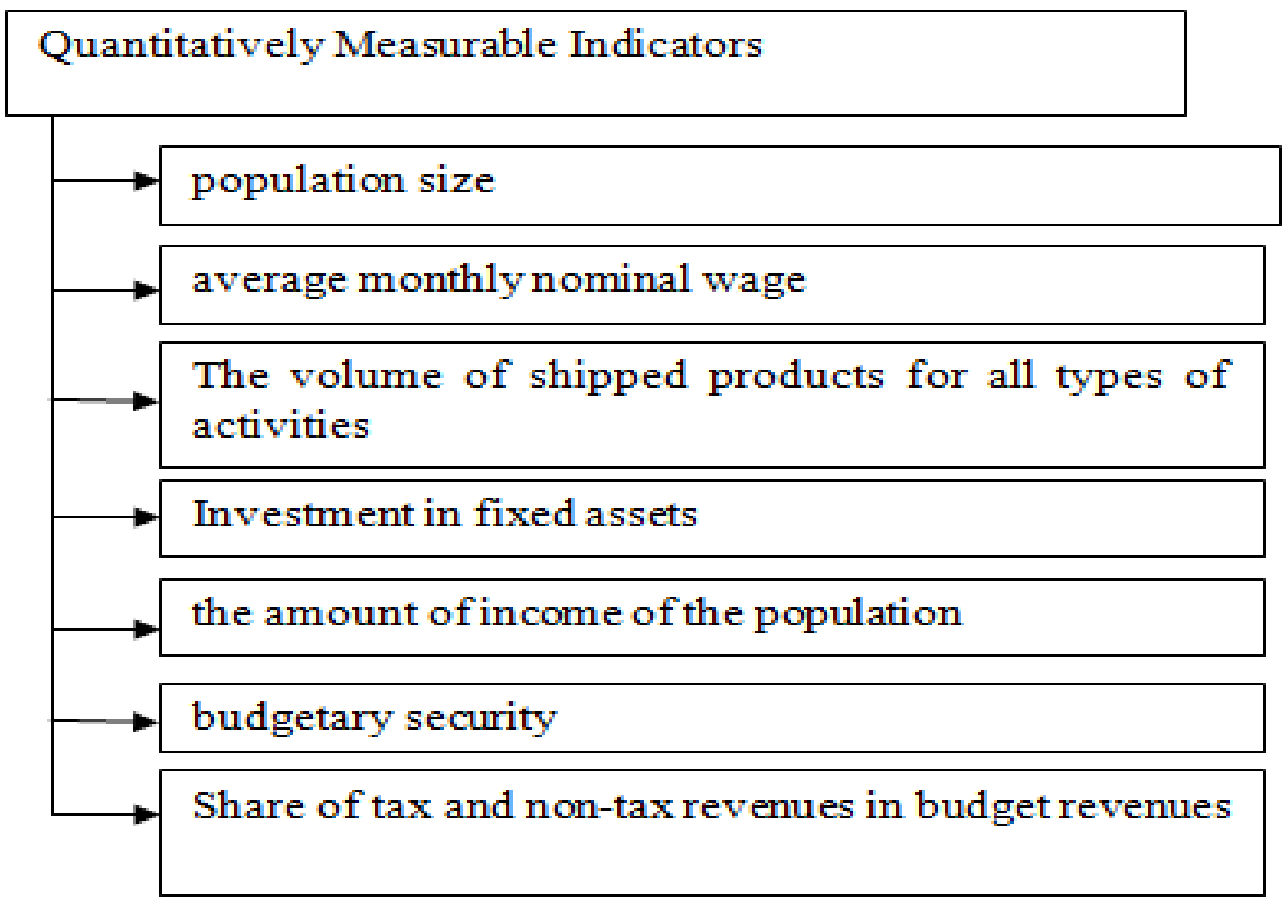

Fig. 4. Indicators for mathematical modeling in predicting socio-economic development 
In this case, the main task of the software will be to assess the quality of the equations that will be obtained, and the integration of individual equations into a single computational scheme. Linear models will be most preferred.

Next, we present as an example of mathematical model that allows us to predict the formation of cash incomes of the population, which include incomes from wages, property, social transfers, entrepreneurial activity and other incomes.

Each of the selected sources are calculated strictly by a formula model which depending on certain factors.

Suppose that $\left(X_{\text {or }}^{\mathrm{t}}\right)$ wages parameters, were obtained the following regression equation model:

$$
X_{\text {от }}^{t}=5693,19+7,66 \times N_{\text {зан }}^{t} \times R_{3 \Pi}^{t}
$$

where $N_{\mathrm{saR}}^{\mathrm{t}}-$ the average of employees of enterprises and organizations;

$R_{3 \pi}^{t}$ - average monthly salary

In favor of the quality of the model indicate values of Fisher's statistics $\mathrm{F}=$ $23,45, \mathrm{t}(\mathrm{a})=3,08, \mathrm{t}(\mathrm{b})=4,84$ with variable $x_{\mathrm{or}}^{\mathrm{t}}$, coefficient of determination $\mathrm{R}^{2}=$ 0,82 .

For the property income parameter $\left(X_{\text {co }}^{t}\right)$ the following regression model was obtained:

$$
X_{\text {соб }}^{t}=4599,47+0,31 \times X_{\text {соб }}^{t-1}
$$

In favor of the quality of the model indicate values of Fisher's statistics $\mathrm{F}=$ $48,64, \mathrm{t}(\mathrm{a})=5,68 \mathrm{t}(\mathrm{b})=2,21$ with variable $X_{\text {coб }}^{\mathrm{t}-1}$, coefficient of determination $\mathrm{R}^{2}=$ 0,75 .

The next parameter which it is necessary to present the regression equation of the social transfers model:

$$
X_{\text {от }}^{t}=-409,19+15,39 \times N_{\text {пенс }}^{t} \times R_{\text {пенс }}^{t}
$$

where $N_{\text {пенс }}^{t}-$ the number of pensioners;

$R_{\text {пенс }}^{t}-$ the average size of accrued pension.

In favor of the quality of the model indicate values of Fisher's statistics $\mathrm{F}=$ $991,48, \mathrm{t}(\mathrm{a})=2,01 \mathrm{t}(\mathrm{b})=31,49$ with variable $X_{\mathrm{rp}}^{\mathrm{t}}$, coefficient of determination $\mathrm{R}^{2}=$ 0,99 .

An important parameter is an indicator as income from business activities, this indicator will be in the following form: 


$$
X_{\text {mp }}^{t}=12005,75+0,253 \times Q_{\text {торг }}^{t}
$$

where $Q_{\text {торг }}^{t}-$ retail trade turnover.

In favor of the quality of this model indicate values of Fisher's statistics $\mathrm{F}=$ $35,71, \mathrm{t}(\mathrm{a})=17,33 \mathrm{t}(\mathrm{b})=1,88$ with variable $X_{\mathrm{mp}}^{\mathrm{t}}$, coefficient of determination $\mathrm{R}^{2}=$ 0,76 .

The regression equation model (5), which will be specified by us in the framework of an equation for such a parameter as the incomes of the population (Y):

$$
Y_{t}=375,79+1,02 \times\left(X_{\text {от }}^{t}+X_{\text {соб }}^{t}+X_{\text {тp }}^{t}+X_{\text {mp }}^{t}\right)
$$

The quality of this model is confirmed by the values of Fisher statistics $\mathrm{F}=$ $541,17, \mathrm{t}(\mathrm{a})=2,18$ and $\mathrm{t}(\mathrm{b})=23,26$ with variable $Y_{\mathrm{t}}$, coefficient of determination $\mathrm{R}^{2}$ $=0,99$.

Based on the fact that the parameters of the economic system are probabilistic, unstable, and there is also the possibility of various risks, when forecasting socioeconomic development, it is imperative to carry out the calculation based on the possible three scenarios: conservative, basic and target.

The parameters of the socio-economic development of the municipality are external parameters. The dynamics of investment in fixed assets, the growth rate of wages and the budget policy of the municipality are internal factors.

Based on this forecast, it is assumed that the economy will focus on an investment development model while maintaining external conditions at the level of the base case, therefore, the presented mathematical model and the forecast that will be obtained as a result of its decision is one of the most effective tools that supports managerial decision-making, but do not forget that the use of the model should be used directly by the person who will interpret the decisions made.

\section{Conclusions.}

Mathematical modeling, which was previously used in most engineering fields, has changed significantly over the past decades. The main reason for this is the development of digital technology. Therefore, mathematical modeling is currently used in areas such as economics, education, medicine, etc., within the framework of the work, a mathematical model is presented that allows solving such a problem as effective forecasting of the socio-economic development of a municipality.

For construction a mathematical model used regression equations, the solution of which with the help of software allowed to make the right managerial decisions 
regarding the forecast for the development of the municipality according to three scenarios: conservative, basic and target.

\section{References}

1. Abdykarimova, A.T., Application of information technology in mathematical modeling. Collection of scientific articles of the IV International scientific-practical conference: Publishing House: Southwestern State University (Kursk), pp. 8-12, (2013).

2. Volkova, L. F., using of information technology in mathematical modeling. Materials of the International scientific-practical conference, Publishing House: Central Russian Institute of Management - Branch of RANEPA (Oryol), pp. 41-45, (2014).

3. Gareeva, G. A., Technologies of Information in Economic and Mathematical Modeling. International Journal of Experimental Education : Academy of Natural Sciences Publishing House (Penza), 5(2), pp. 255-255, (2015).

4. Draisis, Y.I. Actual problems of mathematical modeling of information technologies. International Scientific and Practical Conference, Publishing house: Federal State Budgetary Institution of Science Sochi Research Center of the Russian Academy of Sciences (Sochi). pp. 25 ( 2017).

5. Zvyagin, L.S. Mathematical modeling and a new paradigm of social development in the modern economyEconomics and Management: Problems, Solutions. Publisher: Publishing House "Scientific Library" (Moscow). 7(5). Pp. 5$9,(2018)$,

6. Zmeeva, Yu.V., Information technologies in mathematical modeling of economic processes. Publishing house: Educational institution "Minsk Innovative University" (Minsk). V. 25, pp. 72-73, (2016).

7. Smetanina, A.O., Ivakhnenko N.N., Modern trends in the development of means of economic and mathematical modeling.International Scientific and Practical Conference: in 10 parts. Publishing house: Omsk Academy of Humanities (Omsk). pp. 116-118, (2013).

8. Pavel P., Vladimir B., Mathematical Models of Economic Systems. pp. 2832, (2019).

9. Steven R. Dunbar Mathematical Modeling in Finance with Stochastic Processes URL: https://www.math.unl.edu/ sdunbar1/ MathematicalFinance/ Course Info/BookProposal/mathfinance_book.pdf 
10. Michael A., An Introduction to Mathematical Modelling URL: http:// www.mtm.ufsc.br/ daniel/matap/IntMatMod.pdf.

11. Pavlov Y., Mathematical modelling of socio-economic processes and systems.V. 2,pp. 84-87, (2018). 